\title{
CORRECTION
}

View Article Online

View Journal I View Issue

\section{A) Check for updates Correction: The photocatalytic role of electrodeposited copper on pencil graphite}

Cite this: Phys. Chem. Chem. Phys., 2018, 20, 5983

Arathi P. J., ${ }^{a}$ Seemesh Bhaskar, ${ }^{b}$ Rajendra Kumar Reddy G., ${ }^{a}$ Suresh Kumar P. ${ }^{a}$ and Ramanathan $\mathrm{V}{ }^{* a}$

DOI: $10.1039 / c 8 c p 90037 j$

Correction for 'The photocatalytic role of electrodeposited copper on pencil graphite' by Arathi P. J. et al., Phys. Chem. Chem. Phys., 2018, 20, 3430-3432.

rsc.li/pccp

The authors would like to correct the following errors in the published article:

(1) In the caption for Fig. 3(c), "SERS" should read "Raman spectrum".

(2) In Table 1, the assignment for $3051 \mathrm{~cm}^{-1}$ should not include the S-H stretch $(\nu \mathrm{SH})$.

The Royal Society of Chemistry apologises for these errors and any consequent inconvenience to authors and readers.

${ }^{a}$ Department of Chemistry, SASTRA Deemed to be University, Thanjavur, Tamil Nadu, India. E-mail: vraman.iitk@gmail.com

${ }^{b}$ Department of Chemistry, SSSIHL, Prasanthi Nilayam, Anantapur, Andhra Pradesh, India 